\title{
Referral for first glaucoma surgery in Europe, the ReF- GS study
}

Citation for published version (APA):

Hollo, G., Schmidl, D., Hommer, A., Stalmans, I., Daphne, T., Fichtl, M., Ruzickova, E., Rezkova, L., Bron, A. M., Hoffmann, E. M., Klezlova, A., Erb, C., Zimmermann, N., Kothy, P., Gandolfi, A., Varano, L., Ungaro, N., Januleviciene, Kuzmiene, L., ... ReF-GS Investigators (2019). Referral for first glaucoma surgery in Europe, the ReF-GS study. European Journal of Ophthalmology, 29(4), 406-416. https://doi.org/10.1177/1120672118791937

Document status and date:

Published: 01/07/2019

DOI:

10.1177/1120672118791937

Document Version:

Publisher's PDF, also known as Version of record

Document license:

Taverne

Please check the document version of this publication:

- A submitted manuscript is the version of the article upon submission and before peer-review. There can be important differences between the submitted version and the official published version of record.

People interested in the research are advised to contact the author for the final version of the publication, or visit the DOI to the publisher's website.

- The final author version and the galley proof are versions of the publication after peer review.

- The final published version features the final layout of the paper including the volume, issue and page numbers.

Link to publication

\footnotetext{
General rights Owners
rights.

- You may freely distribute the URL identifying the publication in the public portal. please follow below link for the End User Agreement:

www.umlib.nl/taverne-license

Take down policy

If you believe that this document breaches copyright please contact us at:

repository@maastrichtuniversity.nl

providing details and we will investigate your claim.
}

Copyright and moral rights for the publications made accessible in the public portal are retained by the authors and/or other copyright owners and it is a condition of accessing publications that users recognise and abide by the legal requirements associated with these

- Users may download and print one copy of any publication from the public portal for the purpose of private study or research.

- You may not further distribute the material or use it for any profit-making activity or commercial gain

If the publication is distributed under the terms of Article $25 \mathrm{fa}$ of the Dutch Copyright Act, indicated by the "Taverne" license above, 


\section{Referral for first glaucoma surgery in Europe, the ReF-GS study}

\author{
Gábor Holló', Doreen Schmidl2 and Anton Hommer; \\ for the ReF-GS Investigators
}

\begin{abstract}
Purpose: To analyze the appropriateness of referrals for incisional glaucoma-surgery in Europe. Methods: Referrals for the first open-angle glaucoma surgery between January and October 2017 were analyzed in 18 countries: 8 “old” European Union, 7 "new” European Union and 3 non-European Union European countries.

Results: Most eyes had primary open-angle or exfoliative glaucoma. The average mean deviation was $-13.8 \mathrm{~dB}$ with split fixation in $44.3 \%$. No structural progression analysis was made before the referrals. The most common medications were the combination of a prostaglandin analog, timolol and a carbonic anhydrase inhibitor (30.0\%), and all other combinations comprising $\geqslant 3$ molecules (33.8\%). Laser trabeculoplasty was reported in only $18.4 \%$. Of the 294 referrals, $41.5 \%$ were appropriate and timely, 35.0\% appropriate but later than optimal, and $17.6 \%$ appropriate but too late (minimal vision maintained). The treatment period was significantly longer (median: 7 years) in the "old" European Union countries than in the other groups ( 3 and 2 years, respectively). No between-group differences were seen in intraocular pressure and mean deviation, but the non-European Union group referred the patients at significantly lower cup/disk ratio and eye drop usage than the other groups. Split fixation was significantly more common in the "old" (60.6\%) than the "new" European Union countries (38.7\%), and in both EU country-groups than in the non-European Union countries (I3.6\%). Conclusions: Of 294 European open-angle glaucoma referrals for first glaucoma-surgery, 4I.5\% were completely satisfactory. The damage was typically advanced, and the care varied considerably among the countries. This suggests that further efforts are necessary to improve glaucoma care in Europe.
\end{abstract}

\title{
Keywords \\ Blindness, Europe, European Union, glaucoma surgery, referral, therapy
}

Date received: 25th March 2018; accepted: 9th July 2018

\section{Introduction}

Successful long-term management of glaucoma is essential for preserving vision and satisfactory vision-related quality of life. ${ }^{1}$ However, glaucoma care is not always successful in clinical practice. In 2010 and 2013, in two European studies, it was shown that detecting glaucomatous disk damage and matching it with the corresponding visual field deterioration remains a problem for many ophthalmologists. 2,3 In 2016, we showed that considerable differences exist between the European countries in terms of ophthalmology training, instrumentation and use of the modern technology. ${ }^{4}$ In 2017 , in a 5-center European study, we found that a considerable proportion of the referrals for glaucoma diagnostics were incorrect. ${ }^{5}$ In addition to visual field progression analysis, in recent years, structural progression analysis with optical coherence tomography (OCT) has become accurate, thus the detection of glaucomatous progression is theoretically easier now than it was some years ago. ${ }^{6}$ It is well established that progression of glaucomatous visual field deterioration increases the risk of falls and causes reading difficulties..$^{7-9}$ Thus, early detection of progression, which makes early

\footnotetext{
'Department of Ophthalmology, Semmelweis University, Budapest, Hungary

2Department of Clinical Pharmacology, Medical University of Vienna, Vienna, Austria

${ }^{3}$ Department of Ophthalmology, HERA Hospital, Vienna, Austria

Corresponding author:

Gábor Holló, Department of Ophthalmology, Semmelweis University, 1085 Budapest, Mária u. 39, Hungary.

Email: hollo.gabor@med.semmelweis-univ.hu
} 
intervention possible, is of great clinical importance. Though long-term progression of glaucomatous visual field deterioration is variable, and eyes may preserve function with nonsurgical treatment, many eyes require incisional surgery to reach and maintain the individual target intraocular pressure (IOP) and to reduce functional progression during the course of the disease. ${ }^{1,10}$ Modern glaucoma surgery is typically safe and does not reduce vision. ${ }^{11,12}$ Nonetheless, many glaucoma specialists in Europe feel that a large proportion of cases are referred to them for incisional glaucoma surgery later than they should be. This impression, however, cannot be satisfactorily verified with individual hospital data or individual country data ${ }^{13,14}$ since in such investigations the number of cases may be relatively small, and the results can be biased.

In the current investigation, conducted on consecutive referrals of open-angle glaucoma cases for surgery in 18 European countries in 2017, we analyzed the appropriateness of the referrals for the patients' first time incisional glaucoma surgery. We investigated the characteristics of glaucoma care before the referral, the status of the referred eyes and patients in the investigators office at the time of the referral, the investigators' evaluation of the appropriateness and timeliness of the referrals, and the distribution of the types of the planned surgeries.

\section{Methods}

The investigation was initiated and conducted by the European Glaucoma Society (EGS) Care Delivery Special Interest Group chairs. All European countries with a national Glaucoma Society or Glaucoma Section of the National Ophthalmology Society were contacted via the EGS national representatives for nomination of glaucoma centers (sites) and principal investigators. The sites were chosen after the positive responses from the selected principal investigators had been collected. A standardized questionnaire was used for data collection. The questionnaire addressed data for the non-surgical treatment period, the status of the referred eye, the evaluation of the referral's appropriateness, and the type of the planned surgery. No additional test or investigation was made for the current study. The research protocol and the questionnaire were approved by the corresponding Institutional Review Board for Human Research, for each site, separately. All applicable institutional and governmental regulations concerning the ethical use of human volunteers were followed.

Consecutive open-angle glaucoma referrals (10-30 per site) between January and October 2017 were evaluated. To be included in the analysis the following 3 criteria had to be met: (1) referral for glaucoma surgery by an ophthalmologist, (2) the first referral for any glaucoma surgery in the patient's life, and (3) the referred patient appeared in the investigator's office between 01 January and 31 October 2017 . The questionnaire comprised four sections: (1) the demographics of the patients and eyes, (2) the clinical and treatment data for the total period before the referral, (3) the clinical data obtained in the investigator's site during the patient assessment, and (4) the principal investigator's opinion of the appropriateness and timeliness of the referral, and the type of the planned surgery. The detailed list of information collected via the questionnaire is given in Table 1. The principal investigators responded either by indicating one of the pre-set response options, or by entering the individual measurement values in the questionnaire, as appropriate. Data for individual countries, all countries and country-groups were investigated. The countries were grouped as "old" European Union (EU) countries: Austria, Belgium, France, Germany, Italy, The Netherlands, Spain and Sweden; "new" EU countries: Czech Republic, Hungary, Lithuania, Poland, Romania, Slovakia and Slovenia, and non-EU countries: Russia, Serbia and Turkey. To standardize the reporting of visual field deterioration, the mean defect values of Octopus perimetry were converted to mean deviation (MD) values of Humphrey perimetry using a conversion formula. ${ }^{15}$ The typical IOP value was determined by the investigators using all under treatment IOP values measured before the referral, for each study eye, separately.

\section{Statistics}

The data are reported in percentage and mean values for descriptive country statistics, and median and quartiles for the statistical comparisons. The statistical analysis was performed using the STATA 6.0 program package. For the comparison of the median country-group values, the Kruskal-Wallis test and the Mann-Whitney test were applied. The percentage values were compared with the Chi-square test. Bonferroni correction was made for the $p$-values. $p$-values less than 0.05 were considered as statistically significant.

\section{Results}

Two-hundred ninety-four completed and eligible questionnaires were returned by 19 principal investigators from 18 European countries (Table 2). There were two centers for Germany which were combined for the analysis. The mean age of the referred patients ranged from 55.4years (Hungary) to 70.2 years (Poland). In the total population, $46.6 \%$ of the patients were males. In 133 cases $(45.2 \%)$ the right eye, in 121 cases $(41.2 \%)$ the left eye, and in 40 cases (13.6\%) both eyes were referred for surgery. The study eye population comprised 153 right eyes $(52.0 \%)$ and 141 left eyes $(48.0 \%)$. Regarding the total population, $27.6 \%$ of the referrals arrived from hospitals different from the principal investigators' departments, $46.6 \%$ from private practices, and $22.1 \%$ from the principal investigators own departments. The data reported for the time elapsed since the diagnosis of glaucoma and the initiation of treatment were practically identical; therefore, we report these results together in the duration of treatment category. The mean 


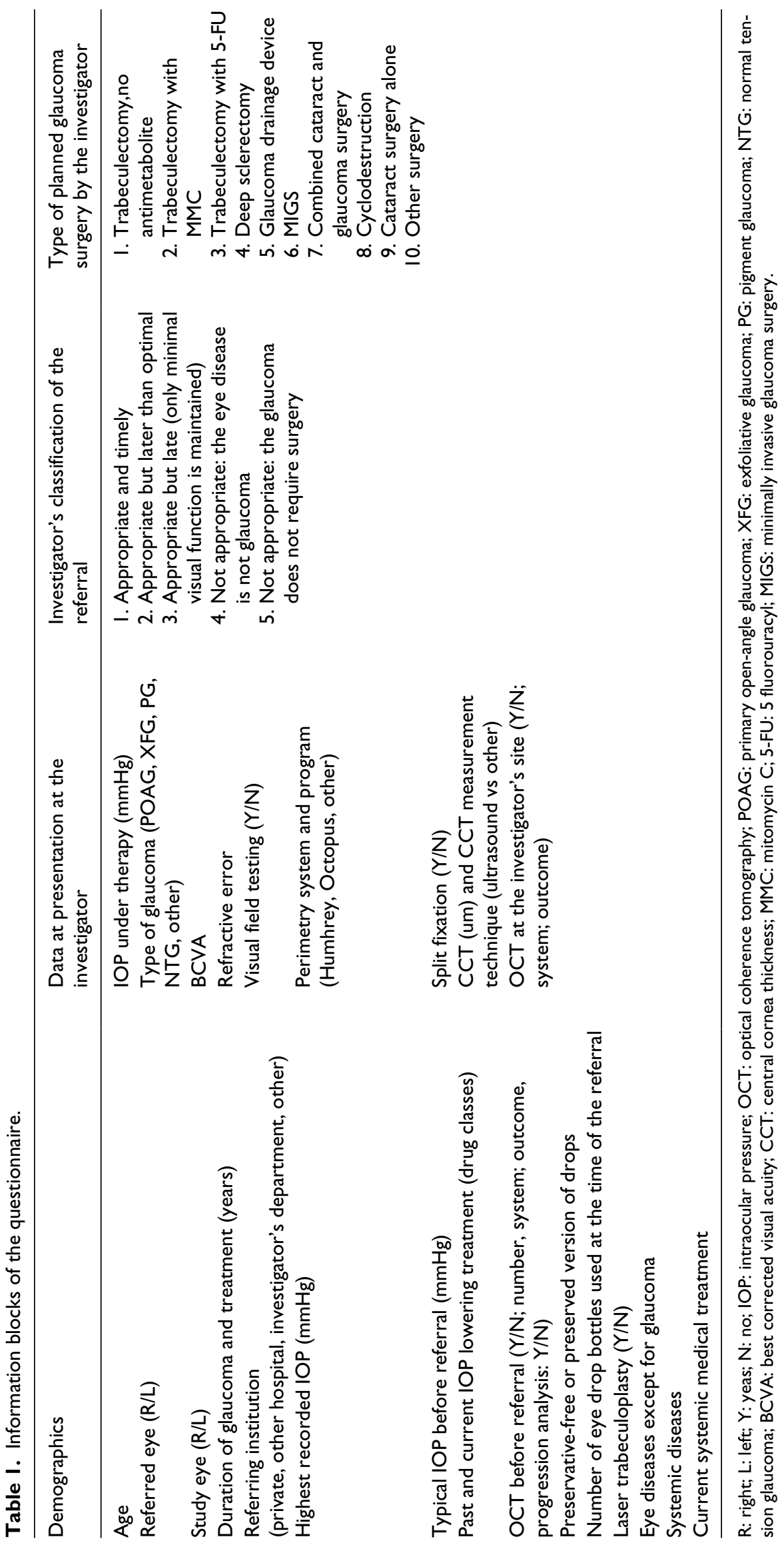




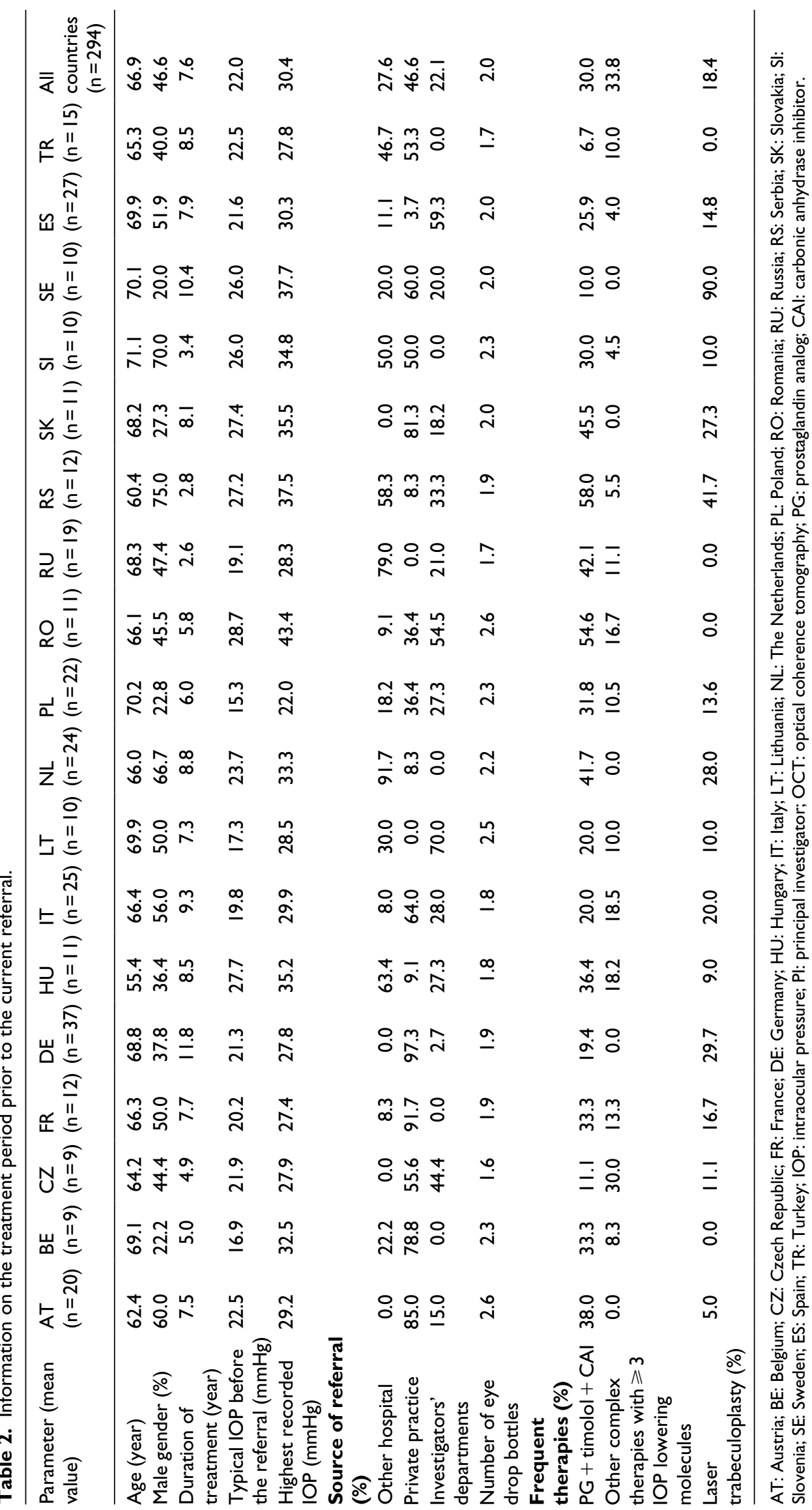


duration of non-surgical treatment ranged from 2.6years (Russia) to 11.8 years (Germany). The typical under-treatment IOP (mean value) ranged from $16.9 \mathrm{mmHg}$ (Belgium) to $28.7 \mathrm{mmHg}$ (Romania). The most common IOP lowering medication was a combined topical medication comprising a prostaglandin analog, timolol and a topical carbonic anhydrase inhibitor (Table 2; 30.0\% in the total population; range: $10.0 \%$ in Sweden and $58.0 \%$ in Serbia). For the total population, a beta receptor blocker monotherapy was reported in $1.4 \%$ of cases, a prostaglandin analog monotherapy in $5.8 \%$, a parasympathomimetic monotherapy in $8.0 \%$, a prostaglandin analog and timolol combination therapy in $7.2 \%$, and a timolol and topical carbonic anhydrase inhibitor combination therapy in $4.8 \%$. A complex IOP lowering medication comprising three or more active IOP lowering molecules, but other than the prostaglandin, timolol and carbonic anhydrase combination shown above, was used in $33.8 \%$ in the total population (Table 2). It ranged from $0 \%$ (Austria, Germany, The Netherlands, Slovakia and Sweden) to $30.0 \%$ (Czech Republic). Within all medication categories, the use of preservative-free medication was reported in $13.6 \%$ of cases. The mean number of eye drop bottles used for the study eyes at the time of the referral ranged from 1.6 (Czech Republic) to 2.6 (Austria and Romania). Laser trabeculoplasty (any type) was performed in $18.4 \%$ of the referred eyes in the total population; there were considerable between-country differences, with the values ranging from $0.0 \%$ (Belgium, Romania, Russia and Turkey) to $90.0 \%$ (Sweden). Other eye diseases were reported in $45.0 \%$ and systemic diseases in $28.2 \%$.

During the treatment period but before the current referral, an OCT test for glaucoma was performed in $22.5 \%$ of all referred cases. When no OCT examination took place, in $38.4 \%$ of the cases the referring ophthalmologists indicated that no OCT instrument was available and in $46.9 \%$ that an OCT examination was not necessary. In $1.1 \%$ of the cases, the OCT examination was not performed due to financial reasons, and in $13.6 \%$ for other reasons (not specified). More than one OCT examination was performed in only $4.4 \%$ of the cases. No software provided progression analysis was done on any study eye.

The type of glaucoma was classified by the investigators (Table 3). Primary open-angle glaucoma (POAG) was the most common type of glaucoma in all countries except for Sweden and Russia, where exfoliative glaucoma (XFG) represented the predominant form. For the total population, POAG was diagnosed in $65.3 \%$ (range: $20.0 \%$ in Sweden and $91.7 \%$ in France). When all countries except for Sweden and Russia are considered, the frequency of POAG in the total population ranges from $44.4 \%$ (Czech Republic) to $91.7 \%$ (France). XFG was reported in $22.5 \%$ in the total population, and the figures ranged from $0.0 \%$ (Belgium and Hungary) to $70.0 \%$ (Sweden). Normal tension glaucoma (NTG) was found in $5.4 \%$ in the total population. The values ranged from $0.0 \%$ (11 countries) to $44.4 \%$ (Belgium). The frequencies of pigment glaucoma and other open-angle glaucomas in the total population were $5.1 \%$ and $0.6 \%$, respectively.

The mean best corrected visual acuity (Table 3 ) ranged from 0.4 (Lithuania and Romania) to 0.9 (Slovakia). The mean spherical refractive error was close to -1.0 diopter in most countries. In Austria and Belgium, it was -3.2 and -3.0 diopters, respectively. The mean under-treatment IOP measured in the investigators' offices was $23.0 \mathrm{~mm}$ $\mathrm{Hg}$ for all study eyes, and ranged from $15.5 \mathrm{~mm} \mathrm{Hg}$ (Poland) to 32.3 (Romania). The central cornea thickness (CCT) was measured in $73.1 \%$ of the cases using ultrasound pachymetry $(80 \%)$ or other methods $(20 \%)$. The mean CCT values were similar in all countries; the overall mean CCT was $540.6 \mu \mathrm{m}$.

A visual field test on the study eye was performed by the investigators in $97.3 \%$ of the cases. The Humphrey Field Analyzer was used in $55.7 \%$, the Octopus perimeter in $26.9 \%$, and any other perimeter system in $13.9 \%$. Most of the tests that did not involve the Humphrey or Octopus systems were performed in the Czech Republic $(100 \%$ of cases) and Poland (86.4\% of cases). A Humphrey 30-2 SITA standard test was used in $27.7 \%$ of cases, a Humphrey 24-2 SITA standard test in 28.5\%, an Octopus Dynamic G test in $21.0 \%$, and an Octopus Tendency Oriented Perimetry (TOP) test in $10.3 \%$. Only MD values determined with the Humphrey Field Analyzer and converted from Octopus mean defect to Humphrey MD were used for the MD calculations. The mean MD was $-13.8 \mathrm{~dB}$ for the total population. The values ranged from $-9.0 \mathrm{~dB}$ (Sweden) to $-20.0 \mathrm{~dB}$ (Romania). Split fixation was found in $44.3 \%$ of the total study population. The reported figures ranged from 5.3\% (Russia) to $88.2 \%$ (Germany). The vertical cup/disk ratio ranged from 0.6 (Turkey) to 1.0 (Slovenia). The mean figure for both vertical and horizontal cup/disk ratios was 0.8 .

For the total population, an OCT examination for glaucoma was performed by the investigators in $34.4 \%$ of the cases. The general outcome of these tests were "within normal limits" in $4.1 \%$ of cases, "borderline" in $9.0 \%$, and "outside normal limits" in $86.9 \%$. An Optovue OCT was used in $5 \%$ of cases, a Cirrhus OCT in $14 \%$, a Spectralis OCT in $42 \%$, a Topcon OCT instrument in $7 \%$, and other systems in $32 \%$. When OCT examination did not take place the reasons for not performing an OCT test were given as follows: not necessary $(46.6 \%)$, not available (3.7\%), financial reasons $(44.2 \%)$ and other reasons $(0.3 \%)$. Other imaging methods (e.g. disk photography, Heidelberg retina tomography or scanning laser polarimetry) were used in $16.3 \%$ of the cases, both as tests added to the OCT examination and as stand-alone tests.

The evaluation given by the investigators on the referrals, and the type of the planned surgery are given in Table 4. An appropriate and timely referral was indicated in $41.5 \%$ of all referrals. Low figures were reported for 


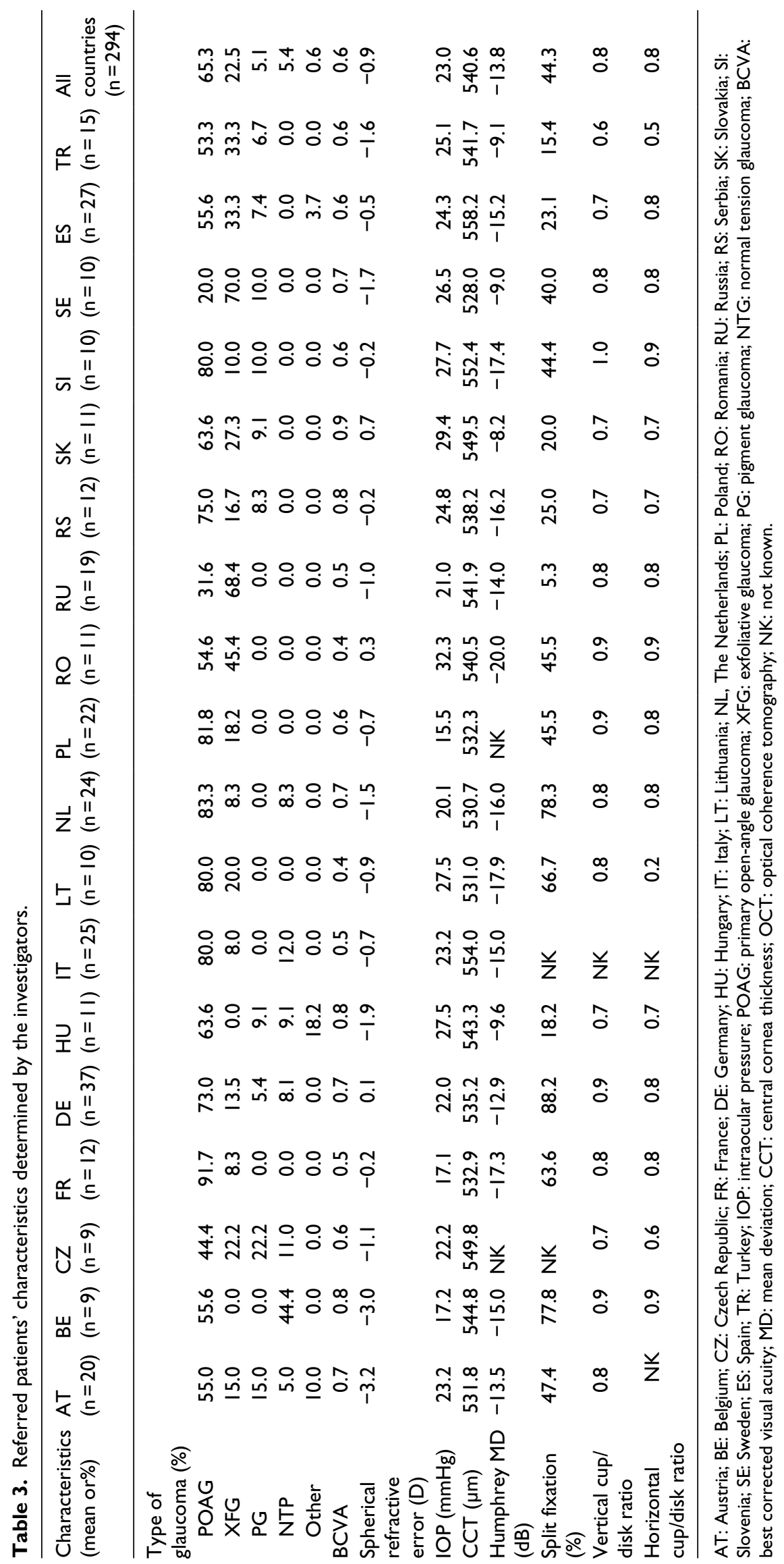


France $(0.0 \%)$, Romania (9.1\%) and Slovenia (20.0\%). For most countries, the figures ranged from $31.8 \%$ to $56.6 \%$. The highest ratio was reported for Belgium $(88.9 \%)$. An appropriate but later than optimal referral was reported in $35.0 \%$ of the cases. The figure was $0.0 \%$ in Belgium, and ranged from $13.3 \%$ (Turkey) to $60.0 \%$ (Lithuania). An appropriate but too late referral, when only minimal visual function remained in the study eye, was found in $17.6 \%$ of all cases. Only 3 of the 18 countries (Hungary, Russia, and Turkey) reported $0.0 \%$; the figures for other countries ranged from $4.2 \%$ to $45.5 \%$. A referral that was not appropriate because the eye disease was not glaucoma was seen in only $0.7 \%$ of cases. A referral that was not appropriate since the existing glaucoma did not require incisional surgery was reported in $4.7 \%$ in the total population. It is interesting that in this category only three countries reported cases, but in all of these three countries, the figures were high: $20.0 \%$ in Austria, $27.3 \%$ in Hungary, and $46.7 \%$ in Turkey.

Most of the planned surgeries (Table 4) were trabeculectomy variants (altogether 56.8\%). The most common surgery was trabeculectomy with mitomycin C application $(27.9 \%)$ followed by trabeculectomy without any antimetabolite (23.1\%). Trabeculectomy with 5-fluorouracyl was planned only in $5.8 \%$, and all cases were planned in Lithuania (100\%), Turkey $(40.0 \%)$ and Germany (2.7\%). Deep sclerectomy and glaucoma drainage device surgery were planned in only $2.7 \%$ and $1.4 \%$ of cases, respectively. In contrast, minimally invasive glaucoma surgery (MIGS) was planned in $11.9 \%$ of cases, combined cataract and glaucoma surgery (mostly phacoemulsification and a MIGS device implantation) in 17.3\% of cases. MIGS and combined surgeries were planned in high percentages of cases only in the "old" EU countries. Cyclodestruction and cataract surgery alone were planned in small percentages $(0.3 \%$ for both surgery types), while other surgery (which included several MIGS versions based on the investigators' comments) represented $8.2 \%$ in the total population with high figures from Turkey, The Netherlands, Germany and Austria.

When the "old" and "new" EU countries and the nonEU European countries were compared no difference was found for any IOP category and the best corrected visual acuity (BCVA) (Table 5). However, the non-EU countries differed significantly from the other two groups in terms of younger patient age, lower number of eye drop bottles used at the time of the referral, and smaller vertical and horizontal cup/disk ratios. The duration of treatment before referral was significantly longer in the "old" EU countries than in the "new" EU and non-EU countries, which did not differ from each other for this parameter. Though no difference in visual field median MD values was found between the country-groups, the ratio of split fixation was significantly higher in the "old" EU group $(60.6 \%)$ than in the other groups, and in the "new" EU country group $(38.7 \%)$, it was significantly higher than in the non-EU country group (13.6\%). We found no difference between the country-groups in the frequencies of the referral evaluation categories.

\section{Discussion}

Our current investigation, in which the referral of open-angle glaucoma patients for their first time incisional glaucoma surgery was investigated using a detailed questionnaire, is based on our previous European investigations. ${ }^{2-5}$ Similar to those studies the current investigation comprised consecutive cases from several European countries. This made it possible to draw conclusion about general aspects of referrals for open-angle glaucoma surgery in Europe. In order to better understand how ophthalmologists currently act when they think that their open-angle glaucoma patients need incisional glaucoma surgery we used consecutive and unselected referrals, all made in 2017. Altogether data on 294 referrals arriving from 19 sites in 18 European countries were analyzed and compared between 8 "old" EU member countries, 7 "new" EU member countries, and 3 non-EU member European countries. The rationale of the comparisons between these three country-groups was that the financial and reimbursement backgrounds are different in the country-groups, but several regulatory standards (e.g. approved glaucoma medications and fixed drop combinations) are similar for all EU member states, while they are variable in the nonEU European countries. Thus, treatment options may vary across the country-groups which, in contrast to the individual countries, all comprise enough cases for statistical comparisons. It is also important that most referrals arrived from three different sources: hospital units other than the investigators' own departments $(27.6 \%)$, private practices (46.6\%), and the investigators' own departments (22.1\%). This distribution suggests that our results reflect real-life practice in Europe.

In the first part of the questionnaire, the data for the whole treatment period before the actual referral were addressed. The most important parameters including the age of the patients, the highest measured IOP, the typical under-treatment IOP, the use of various IOP lowering medication/combination options and laser trabeculoplasty, and the duration of the period under medical and laser treatment prior to the referral varied considerably among the countries. Our data show that the very substantial between-country differences cannot be explained by the different frequencies of the main open-angle glaucoma types. For most countries POAG was the predominant glaucoma type, while in two countries it was XFG. XFG represented at least $10 \%$ of the referred cases in 13 of the 18 countries. This illustrates both the significance of XFG and the improving recognition of this glaucoma type in Europe, which may be a result of the continuous 


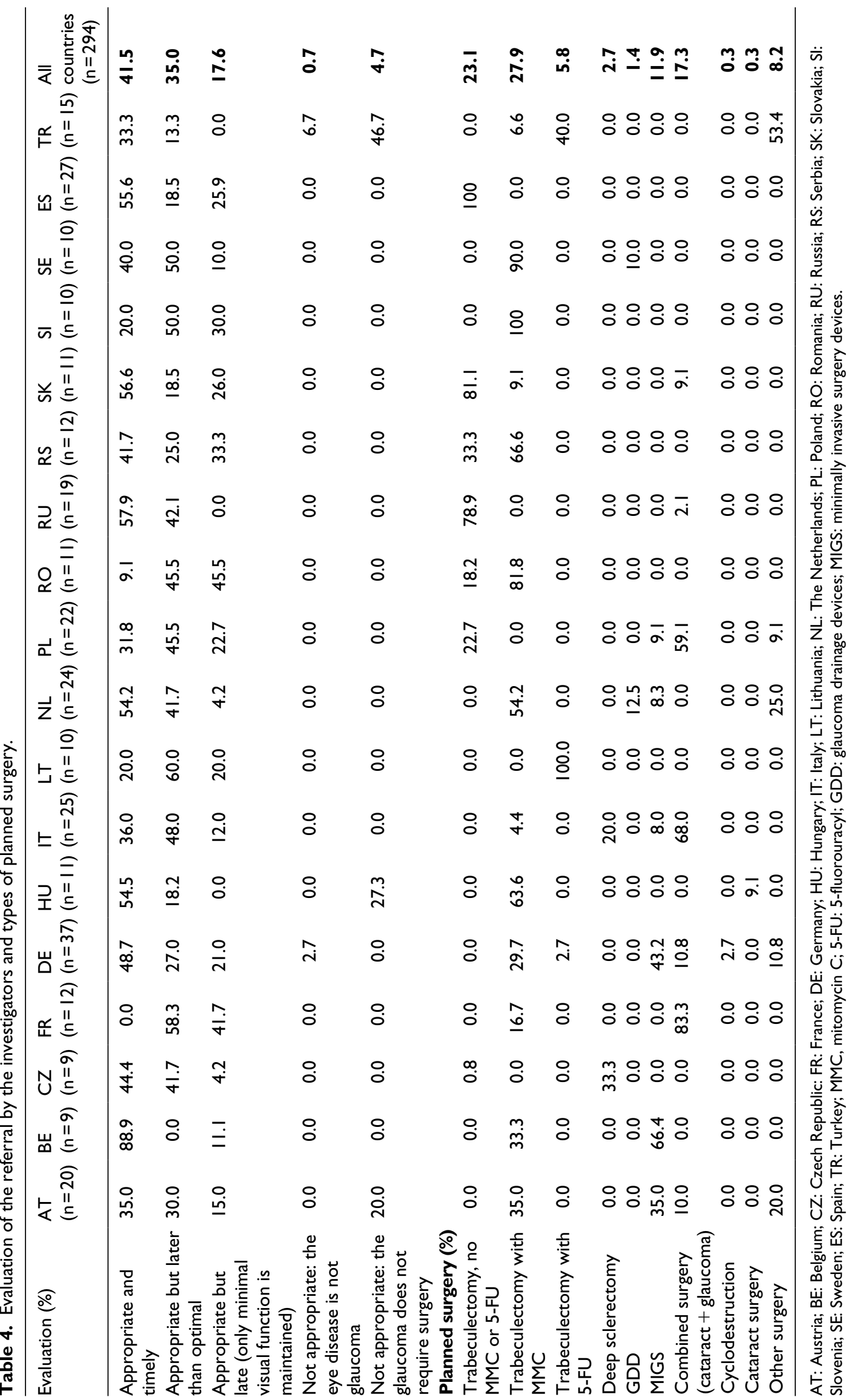


Table 5. Comparison of data from the "old" European Union (EU) member countries, "new" EU member countries and non-EU member countries.

\begin{tabular}{|c|c|c|c|c|}
\hline Parameter & $\begin{array}{l}\text { "Old" EU countries } \\
\text { (I), n= } 164,8 \text { countries } \\
\text { (median, quartiles) }\end{array}$ & $\begin{array}{l}\text { “New” EU countries } \\
\text { (2), } n=84,7 \text { countries } \\
\text { (median, quartiles) }\end{array}$ & $\begin{array}{l}\text { Non-EU countries } \\
\text { (3), } n=46,3 \text { countries } \\
\text { (median, quartiles) }\end{array}$ & p-value \\
\hline \multirow[t]{2}{*}{ Age (years) } & 69.0 & 69.0 & 66.0 & \multirow{2}{*}{$\begin{array}{l}P_{1,2}=0.0153^{*} \\
P_{1,3}=0.0015^{*} \\
P_{2,3}=0.2300^{*}\end{array}$} \\
\hline & $58.5 \quad 77.0$ & $59.0 \quad 76.0$ & 61.071 .0 & \\
\hline \multirow{2}{*}{$\begin{array}{l}\text { Duration of treatment } \\
\text { (years) }\end{array}$} & 7.0 & 3.0 & 2.0 & \multirow{2}{*}{$\begin{array}{l}P_{1,2}=0.0099 * \\
P_{1,3}=0.0009 * \\
P_{2,3}=0.1880 *\end{array}$} \\
\hline & $2.0 \quad 12.0$ & $1.0 \quad 10.5$ & $1.0 \quad 7.0$ & \\
\hline \multirow{2}{*}{$\begin{array}{l}\text { Highest IOP before referral } \\
(\mathrm{mmHg})\end{array}$} & 28.0 & 29.0 & 30.0 & \multirow{2}{*}{$p=0.4298 \#$} \\
\hline & $24.0 \quad 34.0$ & $22.0 \quad 38.0$ & $25.0 \quad 34.0$ & \\
\hline \multirow{2}{*}{$\begin{array}{l}\text { Typical IOP before referral } \\
(\mathrm{mmHg})\end{array}$} & 20.0 & 22.0 & 21.0 & $\mathrm{D}=0.3838 \mathrm{H}$ \\
\hline & $18.0 \quad 25.0$ & $17.0 \quad 27.0$ & $19.0 \quad 24.0$ & $p=0.3838 \#$ \\
\hline \multirow{2}{*}{$\begin{array}{l}\text { IOP at the investigator } \\
(\mathrm{mmHg})\end{array}$} & 21.5 & 23.5 & 22.5 & $P_{1,2}=0.1380^{*}$ \\
\hline & $16.0 \quad 26.0$ & $18.0 \quad 29.5$ & $21.0 \quad 26.0$ & $\begin{array}{l}P_{1,3}=0.156 U^{*} \\
P_{2,3}=0.8664^{*}\end{array}$ \\
\hline \multirow{2}{*}{$\begin{array}{l}\text { Number of eye drops at the } \\
\text { time of referral }\end{array}$} & 2.0 & 2.0 & 2.0 & $P_{1,2}=0.1919 *$ \\
\hline & $2.0 \quad 2.0$ & $2.0 \quad 3.0$ & $1.0 \quad 2.0$ & $\begin{array}{l}P_{1,3}=0.0213^{*} \\
P_{2,3}=0.0045^{*}\end{array}$ \\
\hline \multirow[t]{2}{*}{ BCVA } & 0.6 & 0.7 & 0.7 & $\begin{aligned} P_{1,2} & =0.7633^{*} \\
& =0.0519 *\end{aligned}$ \\
\hline & $0.4 \quad 0.9$ & $0.4 \quad 0.9$ & $0.4 \quad 0.8$ & $\begin{array}{l}P_{1,3}=0.0519 * \\
P_{2,3}=0.068 I^{*}\end{array}$ \\
\hline \multirow[t]{2}{*}{ Vertical cup/disk ratio } & 0.9 & 0.9 & 0.8 & $P_{1,2}=0.1079 *$ \\
\hline & $0.8 \quad 0.9$ & $0.8 \quad 1.0$ & $\begin{array}{ll}0.6 & 0.9\end{array}$ & $\begin{array}{l}P_{1,3}=0.0099^{*} \\
P_{2,3}=0.002 I^{*}\end{array}$ \\
\hline Horizontal cup/disk ratio & 0.9 & 0.8 & 0.7 & $\mathrm{P}_{1,2}=0.1406 *$ \\
\hline & $0.8 \quad 0.9$ & 0.70 .9 & 0.60 .8 & $\mathrm{P}_{2,3}=0.0009 *$ \\
\hline $\begin{array}{l}\text { Humphrey mean deviation } \\
\text { (dB) }\end{array}$ & $\begin{array}{c}-13.3 \\
-19.9-8.1\end{array}$ & $\begin{array}{c}-12.5 \\
-18.3-5.3\end{array}$ & $\begin{array}{c}-11.7 \\
-19.0-5.8\end{array}$ & $P=0.1877 \#$ \\
\hline Split fixation (\%) & & & & $P_{1,2}=0.0120 \pm$ \\
\hline & 60.6 & 38.7 & 13.6 & $\begin{array}{l}P_{1,3}=0.0010 \pm \\
P_{2,3}=0.0120 \pm\end{array}$ \\
\hline $\begin{array}{l}\text { Referral appropriate and } \\
\text { timely (\%) }\end{array}$ & 45.1 & 32.1 & 45.7 & $P=0.1200 \#$ \\
\hline $\begin{array}{l}\text { Referral appropriate but } \\
\text { later than optimal (\%) }\end{array}$ & 33.5 & 41.7 & 28.3 & $P=0.2580 \#$ \\
\hline $\begin{array}{l}\text { Referral appropriate but too } \\
\text { late }(\%)\end{array}$ & 17.7 & 22.6 & 8.7 & $P=0.1380 \#$ \\
\hline
\end{tabular}

IOP: intraocular pressure.

*Mann-Whitney test; \# Kruskal-Wallis test; \pm Chi square test.

education provided by the EGS on this field. ${ }^{1,16}$ On the other hand, NTG was reported in only six countries, and its frequency was at least $10 \%$ in only three countries. This suggests that NTG is probably underrepresented in referrals for surgery in Europe.

It is of particular importance to investigate whether the open-angle glaucoma cases that require incisional glaucoma surgery are referred at an early stage of the disease and at an optimal time. ${ }^{17}$ Some local investigations suggested that this is not always the case in the continental European countries. ${ }^{13,14}$ Our current results showed that visual field deterioration at the time of the referral was advanced for most referred eyes: no country's mean
MD value was in the early stage (better than $-6.0 \mathrm{~dB}$ ), and only 4 countries' mean MD values were in the moderate stage $(-6.0$ to $-12.0 \mathrm{~dB})$. For all the other 12 countries, where Humphrey or Octopus perimeter systems were used, the mean MD values were in the advanced stage (worse than $-12.0 \mathrm{~dB}$ ). The overall mean MD was $-13.8 \mathrm{~dB}$, and split fixation was indicated in $44.3 \%$. This shows that almost one half of the referred open-angle glaucoma eyes had already severe and functionally significant visual field deterioration. This unfavorable result is even more disappointing when the duration of treatment before the referral is taken into consideration. The mean treatment period for the whole population was 
7.6years. The above results clearly show that in Europe many referrals for open-angle glaucoma surgery are late in terms of disease severity and timing.

To better understand the relationship between the timing of the referral for incisional surgery and the maintained visual function we compared the results between the country-groups. Table 5 shows that despite the similar IOP characteristics in all groups in the non-EU country-group the patients were significantly younger at the time of the referral, were treated medically for a significantly shorter period, and had significantly less severe optic nerve head damage than in the other groups. In addition, despite the similarity of visual field median MD values in all groups the percentage of split fixation differed very significantly across the groups: it was $60.6 \%$ in the "old" EU countries, $38.7 \%$ in the "new" EU countries, and only $13.6 \%$ in the non-EU countries. When all the above results are considered the general conclusion is that in the European Union, and particularly in the "old" EU countries, many openangle patients are not referred for surgery at the optimal time and at early damage, but remain on topical medication until their visual field, at least in one eye, is severely damaged. This conclusion is supported by the results of the investigators' evaluation of the referrals: a timely referral was reported in $41.5 \%$, while in $35.0 \%$ the referrals were considered as later than optimal, and in $17.6 \%$ too late, with minimal remaining function in the study eye.

From our data, we cannot provide a clear explanation as to why the referrals are so late in the EU. We did not investigate whether the referring ophthalmologists used visual field progression analysis, which is a part of the standard care; whether the patients themselves wished to postpone surgery; or whether financial reasons caused a delay in the referral. But we did investigate the use of OCT examinations and OCT progression analysis. Unexpectedly, the OCT examinations were performed almost exclusively only once during the long treatment period before the referral, probably to support the diagnosis of glaucoma. OCT progression analysis was not recorded in any of the 294 referrals. This, in accordance with our earlier results, ${ }^{4}$ suggests that structural progression analysis (which can easily draw the ophthalmologist's attention to glaucomatous progression) is still not a part of routine glaucoma care in Europe. On the other hand, it is important to note that $4.7 \%$ of the referrals for incisional glaucoma surgery were in fact unnecessary since no surgery was required tocontrol glaucoma. This indicates that ophthalmologists may need further education with regard to the growing number medical and laser treatment options, at least in the three countries from which the reports of unnecessary referrals arrived.

Finally, we evaluated the distribution of the surgeries planned by the investigators. In general, trabeculectomy variants were the most common options $(56.8 \%$ of all planned surgeries). It was not unexpected that trabeculectomy with mitomycin $\mathrm{C}$ was the most frequent and trabeculectomy with 5-fluorouracyl the least frequent option within the trabeculectomy category, but it was unforeseen that trabeculectomy without any antimetabolite was used in $23.1 \%$ of cases. This can probably be explained by national regulations on the ophthalmological use of antimetabolites and the fact that by definition all planned surgeries were primary surgeries in this investigation. Most of the MIGS, including those combined with cataract surgery, were planned in the "old" EU countries. This result can probably be explained by the more favorable financial/reimbursement conditions in these countries compared to the others, and supports the results of a previous investigation from this region. ${ }^{12}$

Our study has limitations. Due to the retrospective nature of the data collection, a small portion of the data were not clear or available for most categories, and no information on the patients' adherence to the prescribed medication was available. The investigators' opinion on the referral was based on the results of the examinations performed in the investigators' offices, and only $22.1 \%$ of the referrals arrived from the investigators' own departments. Still, some subjective component of the evaluation cannot be excluded. Since most countries provided only 10 cases we did not perform statistical comparisons among the countries. Instead, we grouped the countries with similar backgrounds, and compared country-groups. We intentionally did not analyze the data according to the races of the patients, but we do not believe that ethnicity influenced the treatment and referrals in this European study.

In conclusion, the analysis of 294 consecutive referrals of open-angle glaucoma patients for their first incisional glaucoma surgery in 2017 showed that a considerable proportion of the referrals are still late with advanced visual field deterioration and split fixation, and that OCT progression analysis is still not a part of glaucoma care in Europe. Our results suggest that further education on progression analysis and the determination of optimal timing for incisional glaucoma surgery are necessary in Europe.

\section{Acknowledgements}

The ReF-GS Study Investigators: Vass C, Department of Ophthalmology and Optometry, Medical University Vienna, Vienna-Austria; Stalmans I, Daphné T, Department of Ophthalmology, University Hospitals UZ Leuven, LeuvenBelgium; Fichtl M, Ruzickova E, Rezkova L, Department of Ophthalmology, First Faculty of Medicine, Charles University and General University Hospital in Prague, Prague, Czech Republic; Bron AM, Department of Ophthalmology, University Hospital, Dijon-France; Hoffmann EM, Klezlova A, Department of Ophthalmology, University Medical Center Mainz-Germany; Erb C, Zimmermann N, Eye Clinic Wittenbergplatz, Berlin-Germany; Holló G, Kóthy P, Department of Ophthalmology, Semmelweis University, Budapest-Hungary; Gandolfi A, Varano L, Ungaro N, Department of Ophthalmology, University of Parma-Italy; Januleviciene I, Kuzmiene L, Eye Clinic of Lithuanian University of Health Sciences, Kaunas-Lithuania; Beckers HJM, 
University Eye Clinic, Maastricht University Medical Centerthe Netherlands; Grabska-Liberek I, Majszyk-Ionescu J, Skowyra A, Plichta A, Department of Ophthalmology, Medical Center of Postgraduate Education, Warsaw-Poland; Alina PopaCherecheanu, Department of Ophthalmology, "Carol Davila" University of Medicine and Pharmacy, University Emergency Hospital, Bucharest-Romania; Dorin Chiselita, Department of Ophthalmology, "Gr. T. Popa" University of Medicine and Pharmacy, "Sf. Spiridon" Emergency County Hospital, IasiRomania; Brezhnev A., Baranov V. Department of Ophthalmology, Kursk State Medical University, KurskRussia; Babić N, Miljković A, Eye Clinic KC Vojvodina, Medical faculty, University of Novi Sad-Serbia; Ferková S L, Department of Ophthalmology, Comenius University, Bratislava-Slovakia; Cvenkel B, Department of Ophthalmology, University Medical Center, Ljubljana-Slovenia; Julian GarciaFeijoo, Ruben Sanchez Jean, Department of Ophthalmology, Instituto de Investigaciones Sanitarias Hospital Clínico San Carlos. OFTARED, Universidad Complutense, Madrid-Spain; Botling Taube A, St Erik Eye Hospital, Department of Clinical Neuroscience, Karolinska Institute, Stockholm-Sweden; Irkec M, Kocabeyoglu S, Department of Ophthalmology, Hacettepe University Faculty of Medicine, Ankara, Turkey.

\section{Declaration of conflicting interests}

The author(s) declared no potential conflicts of interest with respect to the research, authorship, and/or publication of this article.

\section{Funding}

The author(s) disclosed receipt of the following financial support for the research, authorship, and/or publication of this article: Gábor Holló received honoraria from Novartis and Santen. Doreen Schmidl reports no financial relationships. Anton Hommer received honoraria from Allergan, Thea, Santen, Aerie.

\section{References}

1. European Glaucoma Society. Terminology and guidelines for glaucoma. 4th ed. Savona: Publicomm, 2014, pp. 129176.

2. Reus NJ, Lemij HG, Garway-Heath DF, et al. Clinical assessment of stereoscopic optic disc photographs for glaucoma: the European Optic Disc Assessment Trial (EODAT). Ophthalmology 2010; 117(4): 717-723.
3. Van der Schoot J, Reus NJ, Garway-Heath DF, et al. Accuracy of matching optic discs with visual fields: the European Structure and Function Assessment Trial (ESAFAT). Ophthalmology 2013; 120(12): 2470-2475.

4. Holló $\mathrm{G}$ and Hommer A. The status of glaucoma diagnostics and care in Europe in 2015: a European survey. Eur $J$ Ophthalmol 2016; 26(3): 216-220.

5. Founti P, Topouzis F, Holló G, et al. Prospective study of glaucoma referrals across Europe: are we using resources wisely? Br J Ophthalmol 2018; 102(3): 329-337.

6. Tatham AJ and Medeiros FA. Detecting structural progression in glaucoma with optical coherence tomography. Ophthalmology 2017; 124(12S): S57-S65.

7. Quaranta L, Riva I, Gerardi C, et al. Quality of life in glaucoma: a review of the literature. Adv Ther 2016; 33(6): 959-981.

8. Baig S, Diniz-Filho A, Wu Z, et al. Association of fast visual field loss with risk of falling in patients with glaucoma. JAMA Ophthalmol 2016; 134(8): 880-886.

9. Boltežar L and Cvenkel B. Reading performance in glaucoma. Acta Ophthalmol 2015; 93(4): e321-e322.

10. Salonikiou A, Founti P, Kilintzis V, et al. Tolerable rates of visual field progression in a population-based sample of patients with glaucoma. Br J Ophthalmol 2018; 102(7): 916-921.

11. Hirooka K, Nitta E, Ukegawa K, et al. Vision-related quality of life following glaucoma filtration surgery. $B M C$ Ophthalmol 2017; 17(1): 661-667.

12. Bron AM, Mariet AS, Benzenine E, et al. Trends in operating room-based glaucoma procedures in France from 2005 to 2014: a nationwide study. Br J Ophthalmol 2017; 101(11): 1500-1504.

13. Holló G, Kerényi Á, Kékedi R, et al. Indication of filtration surgery in Hungary in 2011: we act too late. Ophthalmol Hung 2011; 148(3): 130-135 (in Hungarian).

14. Stürmer JPE and Faschinger C. Do we perform glaucoma surgery too late? Klin Monbl Augenheilkd (in German) 2018; 235(11): 1269-1277.

15. Papp A, Kis $\mathrm{K}$ and Németh J. Conversion formulas between automated-perimetry indexes as measured by two different types of instrument. Ophthalmologica 2001; 215(2): 87-90.

16. Holló $\mathrm{G}$ and Konstas AGP. Exfoliation syndrome and exfoliative glaucoma. 3rd ed. Savona: Publicomm, 2015, pp. 3-197.

17. Mills RP, Budenz DL, Lee PP, et al. Categorizing the stage of glaucoma from pre-diagnosis to end-stage disease. Am J Ophthalmol 2006; 141(1): 24-30. 